Acta Protozool. (2020) 59: 61-65

www.ejournals.eu/Acta-Protozoologica

doi:10.4467/16890027AP.20.005.12673

PROTOZOOLOGICA

Short Communication

\title{
Redescription of Polyplastron alaskum Dehority, 1974 (Ciliophora, Entodiniomorphida), a Rare Rumen Ciliate Species from Domestic and Wild Sheep
}

\author{
Franciane CEDROLA, Marta D’Agosto, Isabel MARTINELE \& Roberto JÚNIO PEDROSO \\ DIAS
}

Laboratório de Protozoologia, Programa de Pós-graduação em Comportamento e Biologia Animal, Instituto de Ciências Biológicas, Universidade Federal de Juiz de Fora, Campus Universitário, CEP 36036-900, Juiz de Fora, Minas Gerais, Brazil

Abstract. The present study redescribes the species Polyplastron alaskum based on morphological characterization and provides, for the first time, data on its infraciliary bands pattern. Polyplastron alaskum was described in Alaskan dall montain sheep (Ovis dalli), and registered again only in the present study, 45 years later, inhabiting the rumen contents of domestic sheep (Ovis aries) in northeastern Brazil. All the taxonomic characters observed in the original description was observed in the present study. The infraciliary pattern in Polyplastron alaskum is slightly different of Diplodinium-type, observed in some ophryoscolecids belonging to the subfamily Diplodiniinae.

Key words: Trichostomatia, Brazilian domestic sheep, ophryoscolecid ciliate

\section{INTRODUCTION}

The genus Polyplastron was established by Kofoid \& MacLennan (1932) and includes six ophryoscolecid species (Ciliophora, Trichostomatia, Ophryoscolecidae): Polyplastron multivesiculatum (Dogiel \& Fedorowa), P. alaskum Dehority, P. arcticum Lubinsky, P. californiense Bush \& Kofoid, P. fenestratum (Dogiel),

Address for correspondence: Franciane Cedrola, Laboratório de Protozoologia, Programa de Pós-graduação em Comportamento e Biologia Animal, Instituto de Ciências Biológicas, Universidade Federal de Juiz de Fora, Campus Universitário, CEP 36036-900, Juiz de Fora, Minas Gerais, Brazil; E-mail: francedrola@gmail.com and $P$. monoscutum (Dogiel). They are taxonomically characterized by two retractable ciliary zones in the anterior end of body, four to five skeletal plates and four to five contractile vacuoles (Williams and Coleman 1992) in the dorsal side of macronucleus. Among those species, only Polyplastron multivesiculatum has a broad geographic distribution and low host specificity (Williams and Coleman 1992). The other five ones are rare and were never found again after the original description. Here, we performed the second report of Polyplastron alaskum, 45 years later, and redescribe this species based on morphological characterization and provides, for the first time, data on its infraciliary bands pattern. 


\section{MATERIALS AND METHODS}

Rumen samples were obtained from 16 domestic sheep (Ovis aries L.) housed in individual stalls and distributed in a completely randomized design with four treatments and four replicates, in the Universidade Federal Rural de Pernambuco, Pernambuco, Brazil. The animals received water and mineral salts ad libitum, and a diet of corn, soybean meal, and vegetable oil. The basal diet consisted of Tifton hay (Cynodon dactylon) (for details see Medeiros et al. 2009). Samples were obtained manually, at slaughter of animals, from the rumen mass center, consisting of $20 \mathrm{~cm}^{3}$ of rumen content, which was fixed in $18.5 \%$ formalin (Dehority 1984). Species identification was based on the descriptions of Dogiel (1927), Kofoid and MacLennan (1932), Bush and Kofoid (1948), Lubinsky (1958), Dehority (1974), and Williams and Coleman (1992). To identify the ciliate, we used an Olympus BX-51 light microscope (600 X and $1000 \mathrm{X}$ magnification) equipped with an Olympus Evolt E-330 digital camera and Image-Pro Plus 6.0 software to perform morphometry on 20 specimens stained with the Lugol's solution (D’Agosto and Carneiro 1999; Cedrola et al. 2015). The orientation of the ciliates for description was adopted from Dogiel (1927): the side closest to the macronucleus was termed the dorsal side, and the opposite one, the ventral side, thus, defined the right and left sides. The infraciliary bands were stained using the silver carbonate impregnation technique (Cedrola et al. 2015; Rossi et al. 2016). The term polybrachykinety denotes infraciliary bands composed of numerous, short and parallel kineties (Fernandez-Galiano 1979). Free-hand drawings were created for observation of the specimens stained with Lugol's solution and after silver carbonate impregnation, under a microscope (Olympus BX-51). All drawings were obtained so that the anterior side of the body was at the top of the page. The species prevalence was determined according to Bush et al. (1997) and the relative abundance was estimated according to Mishima et al. (2009).

\section{RESULTS}

\section{Polyplastron alaskum Dehority, 1974 (Fig. 1, Table 1)}

Elliptical body shape, laterally compressed, and rounded posteriorly. Two retractable ciliary zones, one adoral and one dorsal, at anterior end of body, separated by an inconspicuous and tapered operculum. Complex skeletal apparatus, composed by five skeletal plates. Two plates are located on the right surface of body, primitiva and carina. Primitiva is juxtaposed to the macronucleus, and is wide and long, extending from the anterior portion of the operculum to the posterior body portion; carina is located near the ventral surface of body and present the same length than primitiva, extending from the base of the adoral ciliary zone to the posterior body portion. Three plates are located on the left body surface, tergum, anticarina and scutum. Tergum is located in the dorsal surface of body, and is wide and long; anticarina is located in the middle portion of body, and is wide and short; and scutum is located in the ventral surface of body, and is short and inconspicuous. The anterior end of the left plates was connected by transverse polysaccharide bars. Ectoplasm extend beyond of the body and forms an inconspicuous small lobe. Endoplasm with many food particles, essentially vegetal fibers and starch granules. Long macronucleus, club-shaped, located in the dorsal surface of body, extending from the base of the ciliary zone to the posterior body portion. The elliptical micronucleus is in a depression in the dorsal anterior surface of the macronucleus. Five contractile vacuoles, are located in a line in the dorsal surface of body, each with a conspicuous opening excretory pore. Rectum is a large, rigid and tubular structure located in the posterior end of body, where cytoproct opens.

Oral infraciliature. Oral infraciliature resembles the Diplodinium-type (Ito and Imai 2006), however present some morphological differences. There is composed by an adoral polybrachykinety (AP), vestibular polybrachykinety (VP), a dorsal polybrachykinety (DP) and paralabial kineties (PK). AP involves the buccal opening; VP is long and extends spirally into the vestibule, originating internally by the dorsal side of AP. DP extend laterally along dorsal anterior side of body. Four or five PK close to ventral portion of AP.

Remarks. Polyplastron alaskum slightly resembles Polyplastron arcticum, a rumen ophryoscolecid ciliate described by Lubinsky (1958), inhabiting the rumen contents of Canadian reindeer (Rangifer tarandus Smith).

\footnotetext{
Fig. 1. Polyplastron alaskum Dehority, 1974 recorded in Brazilian sheep. A. Schematic drawing based on specimens after Lugol's solution; B. Schematic drawing of infraciliary bands based on specimens after silver carbonate impregnation; C. Specimen after silver carbonate impregnation; D. Specimen after Lugol's solution staining; E. Specimen after Lugol's solution staining showing the morphogenetic pattern of skeletal plates and ciliary zones. Ma: macronucleus; Mi: micronucleus; CV: contractile vacuole; Ctp: citoproct; Sk: skeletal plate; ACZ: adoral ciliary zone; DCZ: dorsal ciliary zone; AP: adoral polybrachykinety; DP: dorsal polybrachykinety; VP: vestibular polybrachyninety; Sk pr: skeletal plate primordium; ACZ pr: adoral ciliary zone primordium; DCZ pr: dorsal ciliary zone primordium. Scale bars: $20 \mu \mathrm{m}$.
} 

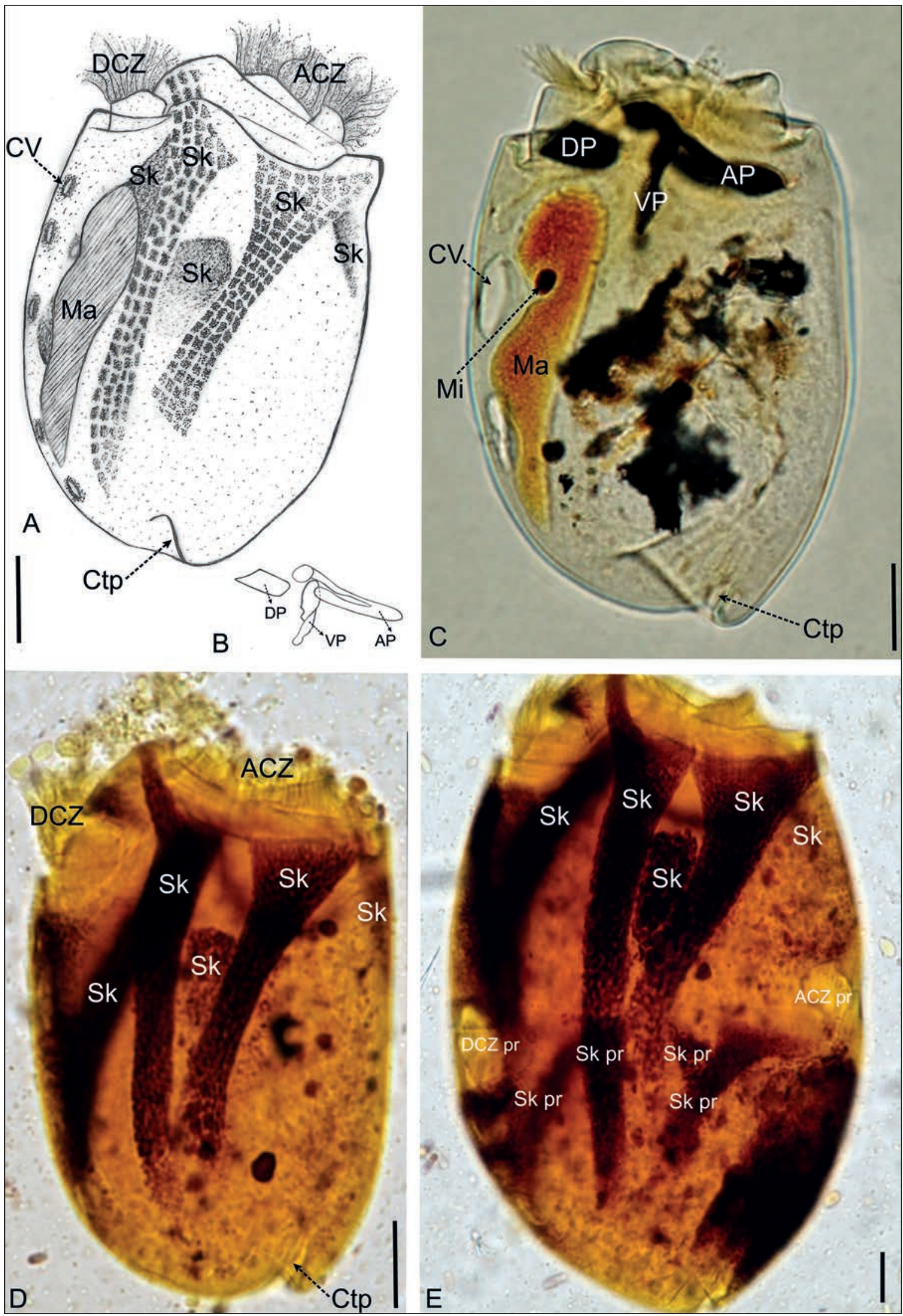
Table 1. Morphometric characterization of Polyplastron alaskum Dehority, 1974 recorded in Brazilian sheep.

\begin{tabular}{lcccccc}
\hline Characters $^{*}$ & Mean & SD & Minimum & Maximum & CV (\%) & $n$ \\
\hline Body length & 101.86 & 3.20 & 98.05 & 109.88 & 3.15 & 20 \\
Body width & 76.54 & 2.19 & 74 & 81.05 & 2.86 & 20 \\
Body length/ body width ratio & 1.33 & 0.02 & 1.30 & 1.37 & 1.45 & 20 \\
Ma length & 63.10 & 1.88 & 60.55 & 66.41 & 2.97 & 8.73 \\
Ma width & 12.40 & 1.08 & 10.87 & 15.01 & 20 & 20 \\
Ma length/ Ma width ratio & 5.12 & 0.45 & 4.35 & 5.81 & 8.78 & 20 \\
Mi diameter & 3.06 & 0.26 & 2.74 & 3.74 & 8.42 & 20 \\
\hline
\end{tabular}

*Based on specimens stained with Lugol's solution. All dimensions in micrometers. Ma: macronucleus; Mi: micronucleus; SD: Standard deviation; CV: Coefficient of variation; $n$ : sample size.

However, P. arcticum displays only four skeletal plates, four contractile vacuoles, and largest body dimensions.

Habitat and hosts. Polyplastron alaskum was originally described in the rumen contents of wild sheep, dall montain sheep (Ovis dalli Nelson) in the vicinity of Cantwell, Alaska (Dehority 1974) and found again only in the present study, in low prevalence $(6.25 \%)$ and relative abundance $(0.8 \pm 1.6)$, inhabiting the rumen contents of domestic sheep (Ovis aries L.) in Recife, Pernambuco, Brazil.

Voucher slides: Type material. Voucher slides with Brazilian population of Polyplastron alaskum (C_Pa_0002_01) were deposited in the collection of the Laboratório de Protozoologia (LabProto), Universidade Federal de Juiz de Fora, Minas Gerais, Brazil.

\section{DISCUSSION}

The genus Polyplastron currently includes six ophryoscolecid ciliate species, in which only Polyplastron multivesiculatum was observed in several host species, domestic and wild, and present a broad geographic distribution (Williams and Coleman 1992). The other five species were not observed again since original description, and should be considered rare species.

There are now a total of at least 137 species of rumen trichostomatid ciliates associated with domestic and wild sheep around the world (Booyse and Dehority 2011; Cedrola et al. 2016). Most of them present a broad geographic distribution. However, some species are rare and have a restricted geographical distribution. Polyplastron alaskum was described by Dehority
(1974) in Alaskan dall montain sheep (Ovis dalli), and registered again only in the present study, inhabiting the rumen contents of domestic sheep (Ovis aries) in northeastern Brazil. The Brazilian domestic sheep were introduced in the country after the colonization process, from different geographical locations. Thus, it is likely that $P$. alaskum were introduced in Brazil along with domestic sheep.

In the morphological and morphometric characterizations performed in the present study, we observed all taxonomic characters present in the original description (Fig. 1; Table 1) and we described for the first time, the oral infraciliature in Polyplastron alaskum. The pattern in this species is slightly different of Diplodinium-type (Ito and Imai 2006), observed in some ophryoscolecids belonging to the subfamily Diplodiniinae, such as Diplodinium Schuberg, Eremoplastron Kofoid \& MacLennan, Eudiplodinium (Dogiel) and in Polyplastron multivesiculatum.

Diplodinium-type infraciliary pattern present the VP straight into the vestibulum (Ito and Imai 2006), instead, in P. alaskum we observed a spiral VP. The infraciliary bands in other Polyplastron species was described only for Polyplastron multivesiculatum (Fernadez-Galiano 1958). According to the author, this species does not display spiral VP. New data on infraciliature of Polyplastron species is necessary to understand whether spiral VP is a autopomorphic character of Polyplastron alaskum.

The present study performed the second report of the species Polyplastron alaskum and redescribed it based on morphological data and description, for the first time, of the infraciliature. 
Acknowledgments. This study was financed in part by Conselho Nacional de Desenvolvimento Científico e Tecnológico (CNPq) (403336/2016-3). CNPq provided research grant to RD (Bolsa de Produtividade PQ). FC would like to acknowledge FAPEMIG for the PhD fellowship. The authors would like to thank Dr. G.A. de Medeiros and Universidade Federal Rural de Pernambuco for the samples of rumen contents.

\section{REFERENCES}

Booyse D., Dehority B. A. (2011) Rumen protozoa in South African sheep with a summary of the worldwide distribution of sheep protozoa. Onderstepoort J. Vet. Res. 78(1): 1-7

Bush A. O., Laffert K. D., Lotz J. M., Shostak A. W. (1997) Parasitology meets ecology on its own terms: Margolis et al. revisited. J. Parasitol. 83: 575-583

Bush M., Kofoid C. A. (1948) Ciliates from Sierra Nevada bighorn Ovis Canadensis sierrae Grinnel. Univ. Calif. Public. Zool. 53: 237-262

Cedrola F., Rossi M., Dias R. J. P., Martinele I., D’Agosto M. (2015) Methods for taxonomic studies of rumen ciliates (Alveolata, Ciliophora): A brief review. Zool. Sci. 32(1): 8-15

Cedrola F., Martinele I., Dias R. J. P., Fregulia P., D’Agosto M. (2016) Rumen ciliates in Brazilian sheep (Ovis aries), with new records and redescription of Entodinium contractum (Entodiniomorphida: Ophryoscolecidae). Zootaxa. 4088(2): 292-300

D’Agosto M., Carneiro M. E. (1999) Evaluation of lugol solution used for counting rumen ciliates. Rev. Bras. Zool. 85: 725-729

Dehority B. A. (1974) Rumen ciliate fauna of Alaskan Moose (Alces americana), Musk-Ox (Ovibus moschatus) and Dall Montain Sheep (Ovis dalli). J. Protozool. 21(1): 26-32

Dehority B. A. (1984) Evaluation of subsampling and fixation procedures for counting rumen protozoa. Appl. Environ. Microbiol. 48: $182-185$

Dogiel V. A. (1927) Monographie der familie Ophryoscolecidae. Arch. Protistenk. 59: 1-288
Fernandez-Galiano D. (1958) La infraciliación en Polyplastron multivesiculatum y su genesis durante la dividión del ciliado. Bol. R. Soc. Esp. Hist. Nat. 32: 89-102

Ferndandez-Galiano D. (1979) Transfer of the widely known "spirotrich” ciliate Bursaria truncatella O.F.M. to the Vestibulifera as a separate order there, the Bursariomorphida. Trans. Am. Microsc. Soc. 98: 447-454

Ito A., Imai S. (2006) Infraciliary band pattern of rumen ophryoscolecid ciliates. Endocytobiosis and Cell Research. 17: 103-110

Kofoid C. A., MacLennan R. F. (1932) Ciliates from Bos indicus II. The genus Diplodinium Schuberg. Univ. Calif. Public. Zool. 41: $53-152$

Lubinsky G. (1958) Ophryoscolecidae (Ciliata: Entodiniomorphida) of reindeer (Rangifer tarandus L.) from the Canadian Arctic II. Diplodiniinae. Can. J. Zool. 36: 937-959

Medeiros G. R., Carvalho F. F. R., Batista A. M. V., Dutra Júnior W.M., Santos G.R.A., Andrade K.B. (2009) Efeito dos níveis crescentes de concentrado sobre as características de carcaça de ovinos Morada Nova em confinamento. Rev. Bras. Zootec. 38: 718-727

Mishima T., Katamoto H., Hori Y., Kakengi V. A. M., Ito A. (2009) Rumen ciliates from Tanzanian short horn zebu cattle Bos taurus indicus and the infraciliatures of Entodininium palmare $\mathrm{n}$. sp. and Enoploplastron stokyi (Buisson, 1924). Eur. J. Protistol. 45: $77-86$

Rossi M., Cedrola F., Dias R. J. P., Martinele I., D’Agosto, M. (2016) Improved silver carbonate impregnation method for rumen ciliate protozoa. Rev. Bras. Zooc. 17: 33-40

Williams A. G., Coleman G. S. (1992) The Rumen Protozoa. Springer, New York, 423 pp

Received on $16^{\text {th }}$ December, 2019; revised on $5^{\text {th }}$ March, 2020; accepted on 31 March, 2020 